\title{
ANÁLISE DOS PARQUES NATURAIS DE CANELA/RS COM ÊNFASE NAS ATIVIDADES DE EDUCAÇÃO
}

\author{
Leonardo Francisco Stahnke ${ }^{1}$, Vânia Medianeira Flores Costa ${ }^{2}$ \\ ${ }^{1}$ Especialista em Educação Ambiental (UFSM) \\ ${ }^{2}$ Professora do Curso de Especialização em Educação Ambiental (UFSM) \\ vaniaflores2006@yahoo.com.br
}

\section{RESUMO}

O presente trabalho teve como objetivo analisar as atividades de Educação Ambiental realizadas nos Parques Naturais do município de Canela/RS, incluindo sua relação com o Turismo Sustentável. Deste modo, inicialmente identificaram-se os parques com características naturais relevantes e elaborou-se um questionário que foi virtualmente respondido pelos seus administradores. O questionário foi composto por 15 questões que objetivavam a avaliar questões amplas e restritas sobre a área dos parques como: sua localização e estruturas, administração, público, aspectos de conservação, relação social e práticas de Educação Ambiental. Dos 17 parques naturais relacionados, 10 responderam ao questionário. A partir deste trabalho verificouse que existe um grande despreparo em relação à administração dos parques sobre sua conservação e gestão. Evidencia-se também o desconhecimento em relação aos fatores abióticos, bióticos e socioeconômicos dos parques, os quais, a maioria, não possui plano de manejo. Há um profundo despreparo dos administradores em relação aos conceitos de Turismo Sustentável e às próprias práticas de Educação Ambiental, fazendo uso desses termos indiscriminadamente como marketing-verde.

Palavras-chave: Parques; Canela; Educação Ambiental.

\section{ABSTRACT}

The present article was analyzed the environmental education activities performed in the Natural Paks of Canela/RS, including its relationship with the Sustainable Tourism. Thus, initially were identified the parks with relevant natural characteristics and developed a questionnaire that was answered through email by their administrators. The questionnaire is composed of 15 questions which aimed to assess broad and restricted issues about the area of the parks, like location and premises, management, public, conservational aspects, social relations and environmental education practices. Of the 17 national parks listed, 10 completed the questionnaire. From this study it was found that there is a much unpreparedness in relation to the administration of the parks on their conservation and management. There is also evidence of lack of knowledge about the abiotic, biotic and socioeconomic facts of the parks, which most don't have any management plan. There is a deep unpreparedness of the directors in relation to the concepts of sustainable tourism and to their own environmental education practices, making use of these terms indiscriminately as green-marketing.

Key-words: Parks; Canela; Environmental Education. 


\section{Monografias Ambientais}

\section{INTRODUÇÃO}

Os modelos de desenvolvimento e os padrões de consumo adotados no mundo continuam produzindo profundas agressões na biosfera e cruéis deformações socioambientais, como desigualdades sociais, desemprego, fome, miséria, violência e outras ainda não tão evidentes, ou imaginadas (DIAS, 2002). Esse modelo também causa uma Crise de Percepção que, segundo Capra (1996), só pode ser solucionada se ocorrer uma mudança radical em nossas percepções, pensamento e valores. Essa mudança deve ocorrer em nosso atual estilo de vida, onde, conforme Dias (2006), se destroem os sistemas de suporte da vida na Terra por meio da poluição das águas que bebemos, do ar que respiramos, dos solos que produzem nossos alimentos, das florestas que garantem a água, o clima ameno, o ar puro e o solo produtivo.

Essa mudança pode e deve se dar por meio da Educação, sobretudo ambiental, que não fragmenta os conteúdos, mas os analisa e os faz entender de forma holística e clara, sem excluir ou discriminar; fazendo com que o ser humano se reconheça como parte do mundo e da sociedade e exerça sua cidadania através de atitudes participativas e adequadas à constituição de um meio ambiente equilibrado e saudável.

Morin (2003) acredita que a Educação deve dedicar-se à identificação da origem de erros, ilusões e cegueiras, além de articular e organizar os conhecimentos para que, assim, se reconheçam e conheçam os problemas do mundo. Segundo Dias (2004), a Conferência Intergovernamental sobre Educação Ambiental, ocorrida em Tbilisi, URSS em 1977, preconiza como categorias de objetivos a consciência, o conhecimento, o comportamento, as habilidades e a participação, tendo como finalidade a identificação e resolução dos problemas ambientais.

Desse modo, tem-se na Educação Ambiental um processo de despertar que deve ser estimulado pelo seu educador, seja na escola, comunidade, em casa, ou qualquer outro espaço de convivência, agindo principalmente sobre os problemas locais, de forma interdisciplinar e independente do público a ser atingido. Para tanto, atividades extra-classe servem como potencializadoras de ações de sensibilização ambiental, sobretudo em áreas naturais, como praças e parques.

Grumbine $(1988$, p. 7) afirma que programas de educação realizados ao ar livre beneficiam não só o lado físico, emocional e espiritual, mas também o intelectual dos aprendizes. Neste sentido, objetivou-se analisar a presença da Educação Ambiental nas ações desenvolvidas nos Parques Naturais de Canela, a fim de verificar o papel educativo que estes têm em relação à sociedade que os cerca.

\section{ÁREA DE ESTUDO}

O presente estudo foi realizado no município de Canela, localizado na Encosta Inferior do Nordeste do Rio Grande do Sul, com área total de $255 \mathrm{~km}^{2}$ e concentração populacional estimada em 2007 de 41.115 habitantes (IBGE, 2009). Apresenta clima subtropical úmido temperado, com elementos típicos da Floresta Estacional Decidual e da Floresta Ombrófila Mista, ambos componentes do Bioma Mata Atlântica, tido mundialmente como área prioritária para conservação da biodiversidade por seu alto grau de ameaça e número de espécies endêmicas (Myers et al., 2000). Além disso, o município serrano apresenta-se como divisor de águas entre as Bacias Hidrográficas do Rio dos Sinos e do Rio Caí, tendo $90 \%$ de suas receitas baseadas em 


\section{Monografias Ambientais}

atividades turísticas (GEOPROSPEC, 2007), sobretudo voltadas à natureza - o que lhe rendeu o título de Capital Nacional do Turismo Ecológico em 1995.

O município é um dos principais destinos turísticos nacionais e internacionais pelo seu diversificado calendário de eventos; clima (quente no verão e com mínimas abaixo de zero no inverno, o que possibilita a ocorrência de neve); sua gastronomia e hotelaria; e seus diversificados parques temáticos ou com características naturais. Dentre estes últimos destacam-se 17 que embora alguns não sejam oficialmente categorizados como Parque, conforme a Lei Federal no11.428 (BRASIL, 2006) - possuem características naturais relevantes para práticas de Educação Ambiental, recreação e lazer em meio à natureza. São eles:

- Floresta Nacional de Canela (FLONA do IBAMA): Floresta localizada na Rua Otavino do Amaral Pires, $\mathrm{n}$ ㅇ 5000, distando $6,5 \mathrm{~km}$ do centro da cidade. Apresenta trilhas de longa distância para trekking, viveiro para recuperação de animais, centro de interpretação ambiental, área de reflorestamento, churrasqueiras e parque infantil. Oficialmente a denominação de FLONA não pertence à categoria de Parque, segundo a Lei do SNUC, embora possibilite a prática de Educação Ambiental, conforme seu Plano de Manejo.

- Parque Estadual do Caracol: Parque localizado na RS 466, km 0 (distando $7 \mathrm{~km}$ do centro da cidade) criado em 1971 e com uma área de 100 ha. Caracteriza-se pela presença da Cascata do Caracol, formada pelo arroio de mesmo nome, que apresenta um queda livre de 131 metros. Conta ainda com um Centro Histórico Ambiental, mirantes, restaurante, área de lazer, feira de artesanato, trilhas ecológicas auto-interpretativas, além de uma escada de 927 degraus (que conduz até a base da cascata) e do trem da Estação Sonho Vivo (que termina em uma tribo indígena e numa cidade-fantasma dos tempos do faroeste). Existe ainda um observatório ecológico que conduz a uma plataforma envidraçada a $27 \mathrm{~m}$ de altura, permitindo uma visão de 360 graus do Parque, com binóculos que dão visibilidade da fauna, flora e de outras cascatas até então desconhecidas ao visitante.

- Parque do Palácio das Hortências (do Governo Estadual): Residência de fim-de-semana dos governadores do Rio Grande do Sul, com uma área verde de 9 ha, localizada na Rua Praça das Nações. Apresenta árvores exóticas, bosque nativo, lagos, trilhas e bancos para descanso, oportunizando caminhadas diárias de canelenses e visitantes.

- Parque do Pinheiro Grosso: Parque inaugurado em 1995, com 4,5 ha e localizado na RS-466, distando cerca de $3 \mathrm{~km}$ do centro. Caracteriza-se pela presença de um pinheiro brasileiro de cerca de 700 anos, tido como o mais antigo do Brasil, com $48 \mathrm{~m}$ de altura e 2,75 m de diâmetro e conta também com a trilha das bromélias, de $300 \mathrm{~m}$. Atualmente encontra-se fechado para melhorias.

- Parque dos Morros Pelado, Queimado e Dedão: Morros localizados a $6 \mathrm{~km}$ do centro da cidade, que permitem a observação da paisagem e cuja geografia proporciona a realização de esportes radicais.

- Parque das Corredeiras: Parque que proporciona a realização de esportes radicais, tendo como característica relevante o Rio Paranhana, onde se realiza a prática do rafting (descida nas corredeiras em botes infláveis).

- Parque de Rodeios: Parque localizado na RS 235 (estrada Canela-São Francisco de Paula), distando $7 \mathrm{~km}$ do centro da cidade. Apresenta relevante arborização e possui infra-estrutura para camping (churrasqueiras, estacionamento, sanitários), servindo como sede anual do Rodeio Nacional de Canela.

- Parque do Caravággio (Saiqui): Parque com uma área de 25 ha, localizado na RS 235 (CanelaSão Francisco de Paula), distando 7 km do centro da cidade. Apresenta relevante arborização, 


\section{Monografias Ambientais}

possui infra-estrutura para camping (churrasqueiras, estacionamento, sanitários), além de capela e Santuário. Anualmente realiza-se no local a Festa de Nossa Senhora de Caravággio.

- Bosque Museu da Araucária de Canela: Reserva Particular do Patrimônio Natural (RPPN) de 12,5 ha, situado na Rua Dr. Ruy Vianna Rocha, vizinha à FLONA de Canela. Considerada como posto avançado da Reserva Biológica da Mata Atlântica, realiza atividades de Educação Ambiental e restauração ecológica da vegetação nativa. Semelhantemente à FLONA, a RPPN não pertence à categoria de Parque, segundo a Lei do SNUC.

- Ecoparque Sperry: Parque localizado no Vale do Quilombo, a 5 km da Rodovia Gramado-Canela (RS 235). Apresenta trilhas auto-interpretativas, cachoeiras, cânions, mirantes, mata nativa, vida animal livre, Centro de Interpretação Ambiental e programas educativos Loboguará. Conta ainda com um restaurante de produtos orgânicos-coloniais (Restaurante Bêrga Motta).

- Parque Vale da Ferradura: Parque localizado na RS 466, km 12, com 400 ha, caracterizado pela presença do vale em forma de ferradura (formado pelo Rio Caí). Apresenta três trilhas ecológicas, mirantes para o Rio Caí e para a cascata do Arroio Caçador (em um cânion com $400 \mathrm{~m}$ de profundidade), churrasqueiras, lancheria, parque infantil e permite o contato da fauna com os visitantes (famílias de quatis circulam entre os visitantes).

- Parque do Teleférico: Parque localizado na Estrada da Ferradura, sem no (500m após o Parque do Caracol). Caracteriza-se pela presença de um teleférico com extensão de $415 \mathrm{~m}$, com vista para a Cascata do Caracol e para o Vale da Lageana. Além disso, o parque proporciona a realização de esportes radicais como trekking, mountain bike e tirolesa, e conta com belvederes, parque infantil e trilhas ecológicas.

- Parque dos Paredões: Parque com 21 ha, que caracteriza-se pela existência de um mirante que permite a visão das divisas Canela, Gramado, São Francisco de Paula e Caxias. Apresenta ainda um cânion sobre o Rio Caí, com diferença de cotas de quase 400 metros, além de camping.

- Parque das Sequóias: O Parque localiza-se na Rua Rodolfo Raimundo, no 1747, tendo como maior atrativo uma coleção de coníferas, dentre as quais se destacam as sequóias americanas e a Ginkgo biloba (a espécie de árvore mais antiga do planeta). Apresenta ainda trilhas de $300 \mathrm{~m}$ e $1500 \mathrm{~m}$, pousada e infra-estrutura de hospedagem e possibilita a realização de caminhadas, corrida de aventura e treinamento empresarial. Do parque saem roteiros de trekking (caminhadas), mountain bike e turismo à cavalo.

- Parque Estação Verde (do Nevoeiro): O Parque localiza-se na Estrada Arnaldo Oppitz, no 601, e conta com trilhas, cascatas, passeios à cavalo, de mini-pôneis e de charretes, pedalinhos, minibichos (mini-porcos, mini-bois, mini-burros, mini-ovelhas, mini-bodes, etc), tiroleza-superman (de quase 500 metros), centro ambiental, de visitantes e restaurante.

- Parque do Sesi: Parque localizado na Rua Francisco Bertoluci, no 504, com 17 ha e distando 2 $\mathrm{km}$ do centro. Apresenta trilhas autoguiadas, cascata, churrasqueiras, praça de brinquedos, salão de festas, cantina, ginásio, cancha de bocha, escolinha infantil, campo de futebol, sanitários, cabanas e área de camping.

- Parque Fazenda da Serra: O Parque localiza-se na RS 426 (estrada que leva à Bom Jesus), possui 4 milhões de metros quadrados e apresenta área verde com lagos, quadras de esporte, piscina, parque infantil e um restaurante típico campeiro. Permite a realização de caminhadas e passeios à cavalo e de charrete, além de possibilitar o conhecimento da gastronomia gaúcha, do processo de ordenha e fabricação de queijos e do Centro de Treinamento e Criação de Cavalos Crioulos. 


\section{Monografias Ambientais}

\section{METODOLOGIA}

O trabalho apresenta uma análise multicaso, de caráter misto, com análise documental, exploratória e descritiva. Os esforços para a construção deste deram-se por revisão bibliográfica multidisciplinar, envolvendo principalmente as áreas das Ciências Humanas e Ciências Biológicas, a fim de poder elaborar um questionário coeso, que contemplasse questões básicas sobre o tema.

O questionário (Apêndice 1) foi elaborado com base na bibliografia consultada a fim de avaliar questões amplas e restritas sobre a área dos parques, sua localização e estruturas, sua administração, público, aspectos de conservação, relação social e práticas de Educação Ambiental realizados.

O instrumento de avaliação inicialmente foi composto por um cabeçalho - questionando sobre $\mathrm{p}$ nome do parque, área e perímetro, endereço, contatos, nível de administração e unidade gestora responsável; bem como o nome, função e contato do responsável pelas informações respondidas - e 15 questões. Dessas, nove eram de múltipla escolha, quatro eram dissertativas (sendo uma de caráter não obrigatória), e duas mistas, ou seja, cuja resposta se daria por meio da marcação por múltipla escolha acompanhada de um complemento dissertativo.

As questões de número 1, 2, 3, 4, 5, 6 e 15, tinham caráter relacionados à Educação Ambiental, avaliando estruturas, atividades permitidas, atributos naturais presentes, atividades oferecidas, relacionamento com a comunidade local e auto-avaliação. As questões 7, 8 e 9, eram voltadas aos investimentos relacionados à conservação dos parques e seu desenvolvimento técnico-científico. As questões 10,11, 12, 13 e 14 relacionavam-se ao público freqüentador do Parque, seu perfil, quantidade, formas de acesso e meses de maior visitação.

A aplicação do questionário se deu pela submissão virtual desse instrumento - na forma de um anexo em documento Word - aos e-mails constantes nos materiais de divulgação (folhetos) de todos os Parques Canelenses. Aqueles que não apresentavam e-mail nos folhetos, mas possuíam sites, foram contatados por esta forma, e um auxílio da Central de Informações Turísticas de Canela foi solicitado para a obtenção dos e-mails daqueles parques que não divulgaram seus contatos nos materiais de divulgação ou não possuíam material algum para oferecer. Desta forma foram atingidos 16 Parques, sendo o Parque dos Paredões o único que não mantém nenhum meio de comunicação com seus visitantes, sendo contatado por telefone e demonstrando interesse em não participar da pesquisa.

Os questionários foram submetidos juntamente com um texto de apresentação do trabalho, esclarecendo seus objetivos, apresentando o autor e seus contatos para o esclarecimento de possíveis dúvidas quanto ao preenchimento do mesmo.

Esses foram enviados no dia 16/04/2010, tendo prazo de resposta de 15 dias (01/05/2010) e, posteriormente, no dia 15/06/2010, tendo em vista o baixo índice de respostas obtidas na primeira tentativa $(n=3)$. Após o retorno dos questionários, todos os dados foram lançados e tabulados em planilhas do Excel, compondo tabelas e gráficos que foram analisados posteriormente. 
REMOA

\section{Monografias Ambientais}

\section{RESULTADOS E DISCUSSÃO}

O número total de Parques que responderam ao questionário foi de 10 (Quadro 1), sendo apenas três são formalmente instituídos como Unidades de Conservação, segundo a Lei do SNUC: a FLONA de Canela, o Parque Estadual do Caracol e a RPPN Bosque Museu da Araucária.

\begin{tabular}{|l|l|}
\hline Nível de Administração & Nome do Parque \\
\hline Federal & Floresta Nacional do IBAMA (FLONA) \\
\hline \multirow{5}{*}{ Estadual } & Parque Estadual do Caracol \\
\hline \multirow{3}{*}{ Municipal } & Parque do Palácio das Hortências \\
\hline \multirow{3}{*}{ Particular } & Parque dos Morros Pelado, Queimado e Dedão \\
\hline & Parque das Corredeiras \\
\hline & Parque de Rodeios \\
\hline & Parque do Saiqui (Caravágio) \\
\hline & Ecoparque Sperry \\
\hline & RPPN Bosque Museu da Araucária de Canela \\
\hline & Parque Vale da Ferradura \\
\hline
\end{tabular}

Quadro 1 - Relação dos Parques Canelenses que responderam ao questionário.

Quanto à localização dos Parques, observou-se que nenhum dos responsáveis pelo preenchimento do questionário informou o endereço completo da sede, sempre faltando dados como Bairro, CEP e até mesmo o nome da Rua. Quanto à área total de cada parque, verifica-se, por sua soma, que totalizam aproximadamente 1077,5 ha, o que representa cerca de apenas $4,23 \%$ da área municipal, sendo a FLONA a maior, com 517 ha, seguida do Vale da Ferradura, com 400 ha, Parque do Caracol, com 99 ha e o Ecoparque Sperry, com 20 ha.

Em relação as respostas obtidas para a questão número 1, o qual questionava sobre quais estruturas os Parques oferecem ao público, 19\% responderam possuir sanitários, seguido de estacionamento (11\%), quadra de esportes (9\%) e praça de alimentação (7\%). Essa realidade aponta que a maioria dos parques não dispõe nem mesmo de uma estrutura mínima para bem receber seus visitantes, sendo o Parque do Caracol o que atendeu o maior número das estruturas questionadas, com nove itens, seguido pelo Parque Vale da Ferradura, com sete.

Na questão número 2, questionava-se sobre quais atividades de uso público são permitidas dentro do parque, $33 \%$ disseram permitir caminhadas e corridas, seguido de acampamento, com 14\%. Escalada/Rappel e cavalgada foram respondidos por $9 \%$ dos Parques. Importante mencionar a prática exclusiva do vôo livre e tiroleza no Parque dos Morros; o rafting no Parque das Corredeiras; o rally no Vale da Ferradura; e o turismo religioso, com peregrinações, no Parque do Saiqui. As atividades na FLONA ainda aguardam atualização do Plano de Manejo para serem definidas e executadas. Nenhum parque mencionou o motociclismo, a natação e a pesca, embora se saiba que essas duas últimas atividades sejam praticadas no Parque das Corredeiras e no Vale da Ferradura.

$\mathrm{Na}$ questão número 3, questionava-se sobre quais atributos naturais o parque oferece, $31 \%$ dos administradores informaram ser relevante a flora nativa, seguido da fauna nativa (24\%). Quarenta porcento dos Parques admitiram possuir espécies de fauna ou flora exóticas em seu domínio. O relevo acidentado foi valorizado apenas pelo Parque do Vale da Ferradura e dos Morros, embora seja presente em quase todos os demais parques. Da mesma forma ocorre com a 


\section{Monografias Ambientais}

valorização das nascentes e rios, citada por apenas dois parques (Bosque de Canela e Vale da Ferradura).

Quando questionados sobre a realização de atividades de Educação Ambiental, na questão número 4, 7\% dos parques informaram realizá-la, sendo que apenas os parques de Rodeios, Saiqui e dos Morros não o fazem. Estes alegam a essa falta o seu restrito período de atividades (tendo em vista que quase sempre funcionam apenas durante curto evento durante o ano), e o fato de ser um parque aberto e de acesso livre (sem portaria ou responsável no local).

Dentre as atividades realizadas como Educação Ambiental destacam-se as trilhas autoguiadas e os painéis, ambos com 16\%; e as publicações e centro de interpretação ambiental ou de visitantes, com $13 \%$. A administração do Ecoparque Sperry não mencionou a realização de publicações, muito embora se saiba da existência de um boletim de notícias sobre a fauna e flora nativas observadas no Parque, que é enviado via mala-direta virtual aos visitantes. Esse material, embora não impresso, pode ser considerado como publicação, sobretudo porque trás informações pertinentes à percepção ambiental do parque e apresenta periodicidade regular, como em uma revista, estando permanentemente disponível em seu site.

Outro apontamento observado a partir da questão de número 4, foi o de que os jogos ecológicos e o teatro ainda não são instrumentos de Educação Ambiental utilizados em nenhum parque, aparecendo como uma ótima oportunidade de inovação - sobretudo porque o município sedia anualmente o Festival Internacional de Teatro de Bonecos (VIVER SERRA RS, 2005), tendo bonequeiros no município, que poderiam atuar nesse campo socioambiental. Morales (1992), em uma análise sobre os meios interpretativos mais utilizados nos Parques da América Latina, aponta, dentre outros, os jogos ecológicos e o teatro como meios menos utilizados e que precisam ser mais desenvolvidos.

Em relação às ações desenvolvidas pelos parques junto à comunidade e escolas do município (Questão 5), verificou-se muitas respostas evasivas e pouco expressivas dos administradores, não apresentando efetivamente ações pró-ativas com a comunidade local. Merece destaque, por informar a realização de atividades com as escolas, o Ecoparque Sperry, o Bosque de Canela e o Parque do Caracol, sendo que o último oferece ainda a gratuidade de acesso aos canelenses - fator que favorece a visitação, embora se distancie cerca de $7 \mathrm{~km}$ do centro da cidade e a freqüência de transporte coletivo ao local limita-se a três viagens diárias.

As respostas obtidas por meio desta questão evidenciam o forte direcionamento das ações dos parques ao visitante turista - e consequentemente ao lucro trazido por este à cidade quando deveria aliar à conservação. Por meio da mobilização social da população local sobretudo dos moradores lindeiros - os parques potencializariam o sentimento de pertencimento e cuidado da natureza e, consequentemente, sua proteção e sustentabilidade.

É interessante observar que com a ausência de um planejamento para o desenvolvimento local integrado, a exploração comercial do turismo à nível mundial vem contribuindo, desde os anos de 1950, para o desequilíbrio ecológico, desagregação social e perda de valores culturais das comunidades, além de promover danos ao patrimônio histórico. (FONTES, LAGE; 2003, p. 92).

Esta falta de inter-relação com a população local também é corroborada pelas respostas obtidas na questão 6. Quando questionados se há uma avaliação contínua da interação do parque com o público, 78\% dos administradores informam que não, sendo o Parque do Caracol e do Vale da Ferradura os únicos que disseram o fazer. O primeiro diz que esta avaliação é feita diariamente, diretamente com o visitante; enquanto que o segundo diz usar seus instrumentos de comunicação 


\section{Monografias Ambientais}

(site, e-mail e telefone) para receber estas avaliações, tentando viabilizá-las sempre que pertinentes. Percebe-se que nenhum dos parques fez referência à auto-avaliação.

Para Vasconcellos (2006, p. 40), "torna-se fundamental avaliar constantemente se os resultados esperados estão sendo alcançados, se o executado é o que realmente foi planejado e se os recursos estão sendo usados apropriadamente". Isso deveria ser realizado prioritariamente com o público local - sobretudo aqueles que se encontram no entorno dos Parques - de forma a desenvolver, segundo Quintas (2002), um justo equilíbrio na distribuição dos custos e benefícios decorrentes da ação sobre os meios físico-natural e construído, processo denominado de Gestão Ambiental.

Na questão 15, na qual os administradores eram incentivados a apresentar outros aspectos pertinentes à Educação Ambiental realizadas nos Parques, a maioria dos parques expôs a previsão da realização de melhorias futuras para suas instalações ou ações que já desenvolveram no passado. Alguns parques também aproveitaram o espaço dado para valorizar as belezas naturais e sua evolução no recebimento de visitastes e na criação de atitudes sustentáveis.

Quanto à apresentação de fotografias e outros documentos pertinentes à Educação Ambiental dos parques, também incentivada por meio da questão 15 , somente o Parque do Palácio encaminhou fotografias $(n=6)$. O Parque do Caracol e a RPPN Bosque de Canela disponibilizaram, respectivamente, seu Plano de Manejo e Plano de Utilização.

No que compete à previsão orçamentária para a Conservação dos Parques (Questão 7) $82 \%$ dos administradores informaram exercer essa prática, excluindo-se apenas o Ecoparque Sperry que sendo recentemente criado, ainda prioriza investimentos em sua estruturação física e divulgação - e o Parque dos Morros - que não tem rubrica própria para si dentro da gestão municipal. Entretanto, quando se avalia as respostas obtidas para a Questão 8 (O Parque possui algum Plano de Manejo?), verifica-se que o conceito de conservação para a maioria dos administradores refere-se à manutenção das estruturas físicas dos parques, e não em relação à "preservação à longo prazo de todas as comunidades biológicas", conceito fundamental da Biologia da Conservação (PRIMACK, RODRIGUES; 2001, p. 6).

Em relação à elaboração de Planos de Manejo, somente metade dos parques informou possuir, sendo que a RPPN Bosque de Canela possui um Plano de Utilização (elaborado no ano de 2007). O Vale da Ferradura e o Parque do Caracol possuem Planos de Manejo datados de 2007 e todos os demais parques que possuem esse instrumento de conservação, estão com seu documentário defasado em mais de cinco anos - contrariando a Lei Federal no 9.985 que define em seu artigo 27, parágrafo 3ㅜ, que os Planos de Manejo "devem ser elaborados no prazo de cinco anos a partir da data de sua criação" (BRASIL, 2000). A FLONA é o único parque que informou estar em fase de atualização de seu Plano de Manejo, enquanto que o Ecoparque Sperry, por ter sido criado no ano de 2009, ainda possui quatro anos para sua elaboração.

Quando investigado sobre a realização de pesquisas nos Parques, somente $30 \%$ dos Parques disseram permitir e apoiar esse tipo de atividade, sendo a FLONA pesquisada pelos alunos e professores da Universidade FEEVALE, e os Parques do Caracol e do Palácio, por servidores da própria Prefeitura Municipal de Canela. De acordo com estas respostas, e as obtidas por meio das questões 7 e 8 , percebe-se que muito ainda deve ser feito para o conhecimento da biodiversidade dos Parques Canelenses, financiando pesquisas e compartilhando informações de forma a valorizar seu patrimônio ambiental às comunidades locais e também aos turistas que buscam conhecer a região.

Em relação ao perfil do público visitante dos parques (Questão 10), verificou-se que $100 \%$ desses são procurados por turistas, ao passo que a comunidade local não é reconhecida pelos 


\section{Monografias Ambientais}

administradores dos parques dos Morros e das Corredeiras. Este fato pode estar ligado ao fato de que ambos os parques não possuem hoje boa estrutura de acesso, sendo o Parque dos Morros considerado perigoso pela população local - sobretudo pelo grande número de assaltos nesta região da cidade - e o Parque das Corredeiras, cujo acesso é oferecido prioritariamente por empresas contratadas de turismo, cujo rafting é a principal atividade.

Quando se analisa o perfil refinado destes visitantes (Questão 11), verifica-se que a maioria (19\%) são estudantes, seguido por universitários e grupos de terceira idade, ambos com $16 \%$. Esse fato expõe o grande potencial que a escola $e$ as universidades representam como potencializadoras de ações voltadas à conservação e ao exercício de cidadania, auxiliando na formação de pessoas mais comprometidas com a realidade. Outro aspecto notável é o reconhecimento de grupos de terceira idade pelos administradores dos parques, podendo este fato estar relacionado ao maior tempo disponível para a recreação e lazer (decorrentes de uma provável aposentadoria), ao aumento da expectativa de vida brasileira e, até mesmo, a maior valorização e compreensão da natureza que esta fase da vida acumula.

Praticantes de esportes de aventura - como vôo livre e rafting - foram citados como perfil de visitantes do Parque dos Morros e das Corredeiras, respectivamente, sendo o público tradicionalista/rural, o que visita o Parque de Rodeios. Nenhum Parque tem grupos indígenas como visitantes e apenas $4 \%$ informam receber público com necessidades especiais.

As respostas obtidas para a Questão 12 (Qual o número médio de visitantes por ano?), apontaram o número de 371.400 pessoas, sendo que o Parque das Corredeiras, a RPPN Bosque de Canela e o Ecoparque Sperry não responderam a esta questão (Figura 1). O Ecoparque Sperry justificou a sua não resposta à questão pelo fato de que ainda não havia tido completado um ano desde sua abertura.

O Parque mais visitado é o Parque do Caracol, um dos cartões-postais do Estado do Rio Grande do Sul, seguido do Parque do Vale da Ferradura, que dista cerca de $6 \mathrm{Km}$ do primeiro, podendo receber este benefício da visitação de forma indireta. Corrobora-se positivamente a esta evidência o fato de que o Parque do Vale da Ferradura é o mais próximo ao Parque do Caracol em relação aos outros parques que participaram do questionário, além de suas belas paisagens. Talvez a grande redução do número de visitantes no Parque do Vale da Ferradura em relação ao Parque do Caracol esteja na menor divulgação deste por meio de folhetos e outras mídias, ou pelo ainda precário sistema de apresentação do Parque como produto turístico aos seus potenciais visitantes - como escolas, universidades, rede de hotéis, etc, que querem ter seus objetivos específicos alcançados durante a visitação. 
REMOA

\section{Monografias Ambientais}

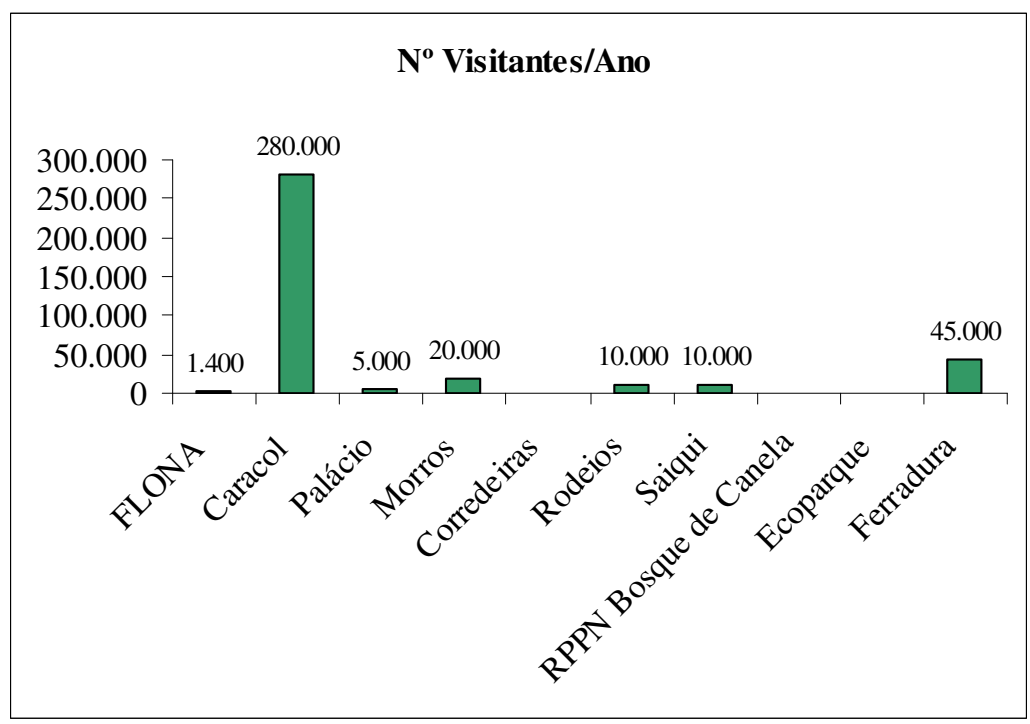

Figura 1 - Número de visitantes por ano nos Parques Naturais de Canela/RS.

Em relação aos meses de maior visitação (Questão 13), a maioria dos Parques informou os períodos de inverno (julho) e verão (dezembro), fato que pode estar ligado aos principais eventos municipais - como o Festival Internacional de Bonecos e o Sonho de Natal, respectivamente - bem como aos seus atrativos climáticos e conciliação com os períodos de férias escolares - que se projetam no planejamento das férias familiares. Somente o Parque do Palácio informou ter uma média se visitação de forma normal no ano, sendo que os Parques de Rodeios e do Saiqui, expuseram possuir visitação pontual nos meses de janeiro e maio, respectivamente - datas em que ocorrem os eventos de cunho tradicionalista (Rodeio Crioulo de Canela) e religioso (Festa de Caravaggio).

Quanto à forma de acesso do público aos parques (Questão 14), todos os Parques informaram receber visitantes de forma direta, representando $45 \%$ dos meios de acesso. As Agências de Turismo são responsáveis por $23 \%$ das visitações, bem como a rede Hoteleira, que contribui com o mesmo percentual. A escola e a igreja foram citadas como outros meios de acesso aos parques, por seu papel aglutinador e organizador.

Por fim, o Parque dos Morros citou a mídia impressa, rádio e folheteria como mecanismos de acesso ao público, embora esses exemplos sejam instrumentos de divulgação que potencializam o acesso direto dos visitantes.

\section{CONCLUSÕES}

Canela é um município gaúcho com expressivas paisagens naturais, banhada por vasta hidrografia, relevo diferenciado e grande riqueza de fauna e flora. Além disso, é destino turístico de centenas de pessoas, que devem respeitar a capacidade de suporte ambiental de suas áreas, mantendo atitudes responsáveis em prol de sua sustentabilidade.

Para que isso efetivamente ocorra, é extremamente importante que as pessoas reconheçam essas áreas como locais importantes para a conservação da biodiversidade. Desse modo, a Educação Ambiental tem papel fundamental, orientando - não só o visitante turista, mas também os munícipes - para o reconhecimento e valorização do ambiente que os cerca e 


\section{Monografias Ambientais}

sustenta. Assim, é de fundamental importância que os Parques Naturais Municipais envolvam a comunidade local em suas atividades, expondo suas características, peculiaridades e atividades, denotando sua importância e dependência.

A partir deste trabalho os Parques Naturais do município de Canela/RS foram analisados, tendo sido permitido, por meio do questionário aplicado, traçar um perfil da relação que os Parques Canelenses mantêm com a Educação Ambiental. Verificou-se que Canela criou Parques em meio a seu relevo acidentado e sua grande malha hídrica, sem preocupar-se muito com a real conservação desses ecossistemas e dos demais seres vivos que os habitam, sobre-explorando suas potencialidades turísticas. Verdade essa evidenciada pela ausência de Planos de Manejo (ou a desatualização destes) e pela própria legislação municipal (Lei Municipal no 1.879/02) o qual dá à Secretaria Municipal de Turismo, Esportes e Lazer - e não à Secretaria de Meio Ambiente e Planejamento Territorial - a Administração dos Parques Municipais por meio de um Departamento.

Art. 94 Ao Departamento de Administração de Parques compete: I - Executar atividades de Administração do Parque do Caracol, do Parque do Flona, do Parque do Palácio, do Parque do Pinheiro Grosso, do Parque das Corredeiras; II - Inventariar, hierarquizar e ordenar o uso e a ocupação de áreas e locais de interesse turístico e estimular o aproveitamento turístico dos recursos naturais que integram o patrimônio turístico do Município com vistas à sua preservação; III - Executar outras atividades correlatas que lhe venham a ser atribuídas ou delegadas (CANELA, 2002).

Além disso, a maioria dos Parques situados no município são particulares, não são legalmente instituídos pelo Poder Público, nem enquadram-se em nenhuma das 12 categorias de Unidades de Conservação instituídas pelo Sistema Nacional de Unidades de Conservação da Natureza - SNUC (Lei no 9985, de 18 de julho de 2000), com exceção da FLONA e da RPPN. Percebe-se, também, um grande despreparo em relação à administração dos parques sobre sua conservação e gestão, sendo poucos ou nulos os investimentos realizados para sua efetiva proteção, visto que essa ação depende de um processo de Educação Ambiental forte, interdisciplinar e em rede, envolvendo todos os atores sociais - locais e visitantes.

Todo processo de Educação Ambiental deve ser iniciado por um profundo conhecimento sobre a realidade local ao qual se pretende trabalhar - no caso, os parques - com a priorização da criação de Planos de Manejo interdisciplinares (incluindo áreas como o design e o turismo) que avalie seus riscos e potencialidades; aliados à inovações de técnicas de Educação Ambiental (que devem ser realizadas por profissionais especializados e qualificados para este fim). Muito embora alguns Parques já possuam estes instrumentos de conhecimento e gestão, faz-se necessário sua leitura e incorporação pelos administradores, de modo que não sirvam somente como registro relictual sobre as características dos Parques, mas sejam efetivamente compreendidas e implementadas.

Outro ponto relevante verificado é o desconhecimento da teoria dos conceitos que os parques "vendem" como produto. Dessa forma, percebe-se que a Educação Ambiental e o Ecoturismo realmente não são o foco principal na maioria dos Parques Naturais presentes no Município, apresentando variações que vão do Turismo Ecocientífico, como evidenciado na FLONA; ao Turismo de Aventura, presente no Parque dos Morros e das Corredeiras. Há também parques que não apresentam objetivos claros quanto às atividades turísticas que realizam misturando práticas agropecuárias, de aventura e lazer indiscriminadamente e até mesmo de forma conflitante - apontando a adoção do termo Ecoturismo como simples marketing-verde. 
REMOA

\section{Monografias Ambientais}

Observa-se, também, que muito embora o instrumento de avaliação propostos neste trabalho tenham atendido aos objetivos previstos, podendo ser utilizados em uma avaliação rápida, é importante que se faça uma avaliação presencial nos parques para verificar o nível de veracidade das informações e/ou de entendimento dos administradores em relação aos critérios analisados.

Ao final desta monografia espera-se que, principalmente por ter sido pioneira em avaliar as atividades relacionadas à Educação Ambiental nos Parques Naturais do Município de Canela, ela sirva de base para uma revisão dos métodos de educação utilizados; para um aprofundamento dos conhecimentos referentes aos fatores abióticos, bióticos e antrópicos dos parques; bem como para uma tomada de consciência e decisões responsáveis em prol da proteção dos ecossistemas municipais e sua biodiversidade. Somente a sinergia de ações entre todos os parques, independentemente do âmbito em que se apresentam, pode efetivamente sensibilizar a população local para a importância destas áreas e, consequentemente, conservá-las, permitindo o turismo sustentável também aos visitantes.

\section{AGRADECIMENTOS}

Agradecimentos especiais aos colaboradores dos Parques Naturais de Canela, Sr. Amílcar José Mielniczuk de Moura, Sr. Ricardo Belarmino da Silva, Sr. Vitor Hugo Travi, Sr. Cilon Estivalet, Sr. Sesefredo Fernandes de Melo, Sr. Marcio Bolsoni e Sra. Lourdes Teresinha Tomazi. Também à Prefeitura Municipal de Canela, com especial respeito aos Secretários de Turismo, Sr, Ditmar Bellmann; Meio Ambiente, Sr. Daniel Schillieper; e Educação, Marluce Fagundes. Também aos colaboradores Paulo Fernando de Almeida Saul, Berenice Gehlen Adams, Márcia Silvana Zimmer Scherer, Ailim Schwambach Theo Vieira Larratéa, Janaína Oppermann, Moisés Teixeira Peixoto, Ingo Hübel, Carmem Rejane Carvalho, Nicole Moreira Veto, Brites Pereira, Caroline Meirelles Dias, Fátima Dorst e Carolina Dávila Domingues. Em especial à Educadora Janine da Silva Demenighi, pelo auxílio na seleção dos parques e análise dos resultados.

\section{REFERÊNCIAS BIBLIOGRÁFICAS}

BRASIL. Lei Federal no 9.985, de 18 de julho de 2000. Dispõe sobre o Sistema Nacional de Unidades de Conservação da Natureza. Disponível em: <http://www.planalto.gov.br/ccivil_03/Leis/L9985.htm>. Acesso em: 1 jul. 2010.

BRASIL. Lei Federal no 11.428, de 22 de dezembro de 2006. Dispõe sobre a utilização e proteção da vegetação nativa do Bioma Mata Atlântica, e dá outras providências. Disponível em: <http://www.planalto.gov.br/ccivil_03/_ato20042006/2006/lei/l11428.htm>. Acesso em: 18 mai. 2010.

CANELA. Lei Municipal no 1.879, de 18 de julho de 2002. Dispõe sobre o ordenamento estrutural dos órgãos Administração Municipal de Canela e dá outras providências.

CAPRA, F. A Teia da Vida: Uma nova compreensão científica dos seres vivos. São Paulo: CULTRIX, 1996. 256p.: il.

DIAS, G. F. Pegada Ecológica e sustentabilidade humana. São Paulo: Gaia, 2002. 264 p. Educação Ambiental: princípios e práticas. 9. ed. São Paulo: Gaia, 2004. 551 p. 


\section{Monografias Ambientais}

Atividades interdisciplinares de educação ambiental: práticas inovadoras de educação ambiental. 2. ed. rev., ampl. E atual. São Paulo: Gaia, 2006. 224 p.

FONTES, E. O.; LAGE, C. S. Apropriação do espaço pelo turismo em Sauípe e seu impacto no desenvolvimento local. In: CORIOLANO, L. N. M. T.; LIMA, L. C. (Org.). Turismo Comunitário e Responsabilidade Socioamiental. Fortaleza: EDUECE, 2003. p. 92-101.

GEOPROSPEC. Plano de Manejo Parque Ecológico Vale da Ferradura. Canela, julho de 2007.

GRUMBINE, E. The University of the wilderness. Journal of Environmental Education, n. 14, p. 3-7, 1988.

HAM, S. H. Interpretacion Ambiental: Uma Guia Pratica para Gente com Grandes Ideas y Presupuestos Pequeños. Colorado, USA: North. Am. Press, 1992. 473p.

INSTITUTO BRASILEIRO DE GEOGRAFIA E ESTATÍSTICA. IBGE Cidades: Estimativa da População 2009. Disponível em: <http://www.ibge.gov.br/cidadesat/topwindow.htm?1>. Acesso em: 10 jun. 2010.

MORALES, J. Classificacion de los Medios Interpretativos. In: Manual para la Capacitación del Personal de Áreas Protegidas. Moore, A Ed. National park Service, USA, 1992.

MORIN, E. Os sete saberes necessários à educação do futuro. 8. ed. São Paulo: Cortez; Brasília, DF: UNESCO, 2003. $118 p$.

MYERS, N.; MITTERMEIER, R. A.; MITTERMEIER, C. G.; FONSECA, G. A. B.; KENT, J. Biodiversity hotspots for conservation priorities. Nature. n. 403, p. 853-858, 2000.

PRIMACK, R. B.; RODRIGUES, E. Biologia da Conservação. Londrina: E. Rodrigues, 2001.

QUINTAS, J. S. Introdução à Gestão Ambiental Pública. Brasília: IBAMA, 2002.

SCHWARTZ, G. M. A arte no contexto da Educação Física. Rio Claro: Motriz, v. 5, n. 1, p. 49-52, Junho de 1999.

VASCONCELLOS, J. M. de O. Educação e Interpretação Ambiental em Unidades de Conservação. Cadernos de Conservação. Ano 03. no 04. Dezembro de 2006. Fundação O Boticário de Proteção à Natureza. Curitiba. 86 p.

VIVER SERRA RS 2005/2006. RBS Publicações. Agosto 2005. Porto Alegre. 215 p. 


\section{APÊNDICE 1}

\section{EDUCAÇÃO AMBIENTAL NOS PARQUES CANELENSES}

Sou biólogo formado pela Universidade do Vale do Rio dos Sinos (Unisinos) e pós-graduando em Educação Ambiental pela Universidade Federal de Santa Maria (UFSM), onde pesquiso aspectos da Educação Ambiental realizada nos Parques Naturais do município de Canela/RS. Para tanto, gostaria de lhe convidar a responder o questionário abaixo. 0 mesmo pode ser enviado para o e-mail leobio@pop.com.br até o dia 01/05/2010, a fim de ser analisado e integrado na compilação de dados de minha monografia. Desde já agradeço pela atenção.

Leonardo Francisco Stahnke - Biólogo CRBio № 58173-03

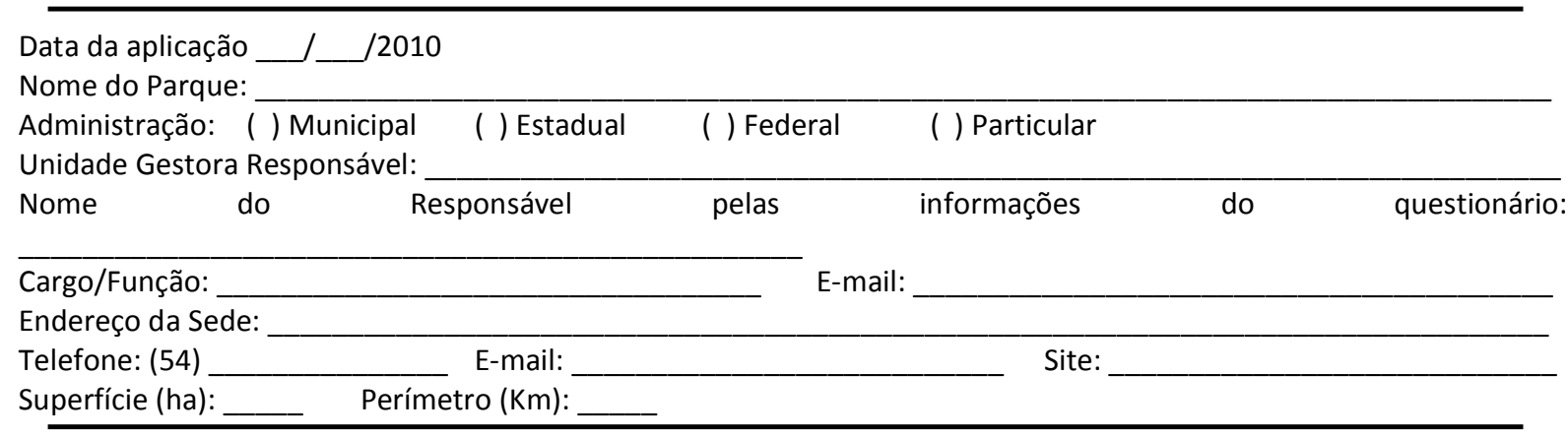

1. Que estruturas são oferecidas ao público?
( ) Quadra de Esportes
( ) Piscina
( ) Cancha de Bocha
( ) Parque Infanti
( ) Área de Camping
( ) Arvorismo
( ) Paintball
( ) Centro de Visitantes
( ) Trilhas
( ) Mirante
( ) Ponte Suspensa
( ) Artesanato
( ) Espaço Comercial
( ) Sanitários
( ) Estacionamento

( ) Praça de Alimentação ( ) Outras:

2. Que atividades de uso público são permitidas dentro do Parque?
( ) Natação
( ) Acampamento
( ) Escalada/Rappel
( ) Tirolesa
( ) Passeio de Charrete/Carroça
( ) Caminhada/Corrida
( ) Motociclismo
( ) Rally
( ) Ciclismo
( ) Cavalgada
( ) Rafting
( ) Pesca

( ) Outras:

3. Que atributos naturais o Parque oferece?
( ) Flora Nativa
( ) Flora Exótica
( ) Fauna Nativa
( ) Fauna Exótica
( ) Cachoeiras
( ) Outras

( ) Sim

4. O parque realiza atividades de Educação Ambiental? ( ) Não

Em caso afirmativo, quais? Marque dentre as opções abaixo e/ou acrescente outras (caso houver).
( ) Centro de Interpretação Ambiental (ou Centro de Visitantes)
( ) Publicações (folders/informativos)
( ) Painéis
( ) Audiovisuais
( ) Exposições Permanentes
( ) Mirantes
( ) Jogos Ecológicos
( ) Atividades Lúdicas
Exposições Temporárias
( ) Palestras
( ) Trilhas Autoguiadas
( ) Trilhas com Guias
( ) Teatro e/ou Representações
( ) Outras:

5. Que ações o Parque desenvolve com a Comunidade local e com as Escolas do município?

6. O Parque avalia continuamente sua interação com o público? ( ) Não

( ) $\operatorname{Sim}$ Em caso afirmativo, de que forma e com que frequência? 


\section{Monografias Ambientais}

8. O Parque possui algum tipo de Plano de Manejo? ( ) Não Em caso afirmativo, quando foi elaborado?
( ) Menos de 1 ano
( ) De 1 a 3 anos
( ) De 3 a 5 anos
( ) Mais de 5 anos

9. Há algum tipo de pesquisa feito (ou em andamento) na área do Parque? ( ) Não Em caso afirmativo, responda:

Título:

Período:

Autores:

Instituição:

10. Qual o perfil do público visitante do Parque? ( ) População Local ( ) Turistas

11. Qual o perfil refinado deste público que freqüenta o Parque?
( ) Escolares
( ) Universitários
( ) Graduados
( ) Com Necessidades Especiais
( ) Terceira idade( ) Escoteiros
( ) Pós-graduados
( ) Indígenas
( ) Outros:
( ) Religiosos
12.
Qual
o
número
médio
de
visitantes
por
ano?

13. Quais os meses de maior visitação?

14. Como o público acessa o parque?

( ) Diretamente ( ) Agências de Turismo

( ) Rede Hoteleira

( ) Outra

15. Se quiser, use o espaço abaixo para escrever algo que ache pertinente sobre a Educação Ambiental realizada no Parque. Imagens também podem ser incluídas. 